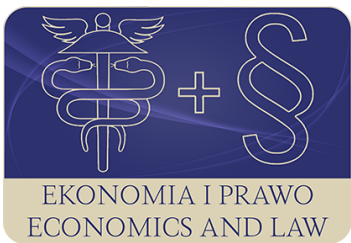

EKONOMIA I PRAWO. ECONOMICS AND LAW

Volume 20, Issue 2, June 2021

p-ISSN 1898-2255, e-ISSN 2392-1625

www.economicsandlaw.pl

EKONOMIA I PRAWO
ECONOMICS AND LAW

ORIGINAL ARTICLE

received 30.03.2021; revised 20.06.2021; accepted 30.06.2021

Citation: Wolak, J. (2021). How will the introduction of the sugar tax affect the consumption habits of households in Poland? Ekonomia i Prawo. Economics and Law, 20(2), 457-473. https://doi.org/10.12775/EiP.2021.028.

\title{
How will the introduction of the sugar tax affect the consumption habits of households in Poland?
}

\author{
JACEK WOLAK \\ AGH University of Science and Technology in Kraków, Faculty of Management, ul. Gramatyka 10, \\ 30-059 Kraków, Poland \\ 曰jwolak@agh.edu.pl \\ D orcid.org/0000-0001-7158-2851
}

\begin{abstract}
Motivation: Numerous scientific studies indicate a significant relationship between the number of sugar-sweetened beverages consumed and the problem of overweight and obesity. This, in turn, is a significant risk factor for many diseases, especially type 2 diabetes. Poland is a country where the consumption of sugar, especially in a processed

form that is dangerous to health, is constantly growing. As a result, now two-thirds of the society are struggling with the problem of overweight, while obesity can be said in every fourth case, the forecasts are even more pessimistic. Recently, a fiscal policy with the use of the "sugar tax" is a popular tool to combat the growing consumption of sweetened beverages. The Polish government is also following this path, and the tax is scheduled to be in force at the beginning of 2021.

Aim: The aim of the study is to analyse the impact of the sugar tax on prices and, consequently, on the future consumption of sweetened beverages and other related goods. Results: Based on the data of the Central Statistical Office concerning household expenditure in 2018, the complete demand model was estimated, considering demographic variables. As a result, the price and profit elasticities of demand for sweetened drinks and related goods were estimated. The results obtained in the study indicate that the introduction of the sugar tax will reduce the consumption of SSB, and the size of the changes depends on the analysed demographic factors. The decrease in consumption of sweetened beverages will increase the interest in beverages with a lower sugar content.
\end{abstract}


Keywords: price elasticity; sugar sweetened beverages; sugar tax; QUAIDS model JEL: D12; H31; I12; L66

\section{Introduction}

Both reduced physical activity and modified diet, in which processed and high-energy food is increasingly involved, are believed to be just some of the consequences of the development of civilization and related to the change of the lifestyle of society.

The WHO data show that in recent decades, these changes have resulted in the problem of overweight and obesity, which increasingly affects people in many countries in the world. This is no different in Poland, where the number of people who have problems with maintaining the correct weight is not yet very high (according to the data for 2016, Poland ranks 21st in Europe), but has been constantly growing for several dozen years. According to the data for 2016 , in the group of men, the number of obese people (BMI>30) is $24.6 \%$, and the number of overweight men $(25<\mathrm{BMI}<30)$ is another $42.9 \%$. Among women, the statistics are only slightly better. The number of obese women is $23.2 \%$, and $29.6 \%$ of adult women are overweight.

Apart from serious health consequences, the obesity epidemic results in higher social costs. According to the data of the National Health Fund for 2017, the costs of medical care in the treatment of diabetes are approximately PLN 1.7 billion, and in the case of other obesity-related ailments in Poland, they reach up to PLN 1.4 billion. Moreover, the estimates of the NHF experts indicate that the costs will increase and according to forecasts in 2025, they will be higher than those indicated by over $20 \%$.

Research points to the fact that the main factor of overweight and obesity is excessive caloric intake, which is highly correlated with the consumption of sweetened drinks (Bes-Rastrollo et al., 2016; Escobar et al., 2013; Malik et al., 2006). It is estimated that in Poland every third eight-year-old drinks soda at least once a week, and two-thirds of teenagers consume energy drinks. Statistics say that in 2010-2020 the consumption of energy drinks increased by more than half $(51.7 \%)$, and the consumption of sweetened drinks in total by $11.1 \%$.

As the obesity epidemic increasingly threatens the health of consumers and significantly increases health care spending's, the governments of various countries around the world are looking for solutions to combat this civilizational problem. Among many ideas for changing the lifestyle (including the promotion of spending leisure time actively), there is a growing discussion about the potential effectiveness of taxing unhealthy food (Bødker et al., 2015). One of the most popular fiscal measures to change the diet through economic factors is the so-called "sugar tax" currently in force in more than 40 countries around the world.

For several years, there has been a discussion about the advisability of introducing a sugar tax in Poland. Despite considerable resistance from the industry, 
the relevant act entered into force on February 14, 2020, and the tax itself came into force from the beginning of 2021.

The act provides for a fixed fee of PLN, 0.50 per liter of sweetened drink (both with sugar and sweeteners) and variable fees: PLN 0.10 for the presence of ephedrine or caffeine in the drink and PLN 0.05 per liter of drink for each gram of sugar over 5 grams per $100 \mathrm{ml}$. It was also established that the maximum amount of tax is PLN 1.20 per liter of drink. Among others, isotonic drinks, and drinks with the participation of min. $20 \%$ fruit, vegetable or fruit and vegetable juice are completely exempt from this tax.

It seems that economic indicators, i.e., the estimation of the price elasticity of demand for selected goods and the knowledge of substitution effects (crossprice elasticity of demand), may be extremely helpful in estimating the effectiveness of the introduced fiscal measures (Harding \& Lovenheim, 2017). Of course, to estimate the changes correctly in the consumption of the goods taken here under consideration, other conditions are required. Above all, information to what extent the tax will be transferred to retail prices and potential actions of producers (e.g., expressed by reducing the sugar content in manufactured goods, advertising campaigns, etc.).

The effect of introducing the sugar levy in Poland was assessed by experts based on the results of foreign research. This study, the purpose of which is to estimate the price and income elasticity of the demand for sweetened beverages, aims to fill this gap.

The rest of the article is divided into five parts. The first presents a review of the literature on research on the demand for sweetened beverages in various countries around the world, as well as studies showing how fiscal decisions can influence on the purchasing decisions of households. The next part discusses the method of constructing the data set used to estimate the price and income elasticities of demand for selected categories of goods. The methodological section discusses the form and properties of the QUAIDS model used in the research and shows the way in which demographic variables were applied to the model. The results of the quantitative analysis with the results for other countries are discussed in the Results chapter. Conclusions from the results obtained in the context of the expected effects of the sugar tax introduced in Poland are described in the Discussion chapter. The work ends with the conclusion part, in which the obtained results are summarized.

\section{Literature review}

Numerous studies have shown that consumption of SSB is associated with the risk of obesity (Malik et al., 2006), which leads to serious health problems, incl. hypertension, type II diabetes (Malik et al., 2010), or ischemic heart disease (Bødker et al., 2015; Härkänen et al., 2018).

One of the considered ways to fight against obesity are fiscal tools, which are introduced in the form of "sugar tax" in countries all over the world. 
In the last decade, the tax was introduced, among others, by Hungary (2011), France (2012), Mexico (2013), UK (2016), Ireland (2018), and from 2021 also by Poland.

In the literature, there has been a discussion about the potential effects of taxing "junk food", which is currently attracting attention. The latest empirical studies of the possible consequences of introducing a "sugar tax" concern many countries, e.g. Australia (Blake et al., 2019; Miller et al., 2019), Brazil (Claro et al., 2012), Chile (Caro et al., 2017b; Guerrero-López et al., 2017), Colombia (Caro et al., 2017a; Vecino-Ortiz \& Arroyo-Ariza, 2018), Denmark (Bødker et al., 2015; Schmacker \& Smed, 2020; Smed et al., 2016), Ecuador (Paraje 2016; Segovia et al., 2020), France (Bernardi et al., 2016), Hungary (Bíró, 2015), Mexico (Barrientos-Gutierrez et al., 2017; Colchero et al., 2015), South Africa (Manyema et al., 2014), UK (Briggs et al., 2013; Breeze et al., 2018; Cornelsen et al., 2019), or the USA (Cawley et al., 2019; Dharmasena \& Capps, 2012; Finkelstein et al., 2010; Jithitikulchai \& Andreyeva, 2018; Lakkakula et al., 2016; Lin et al., 2011).

A significant part of the work indicates the effectiveness of fiscal tools in modelling consumer behaviour. For data from the USA, Finkelstein et al. (2010) showed that the introduction of a $40 \%$ SSB tax should lead to an average weight loss of about $0.6 \mathrm{~kg}$ per year.

Claro et al. (2012) built a log-log regression model based on microdata from Brazil. The results obtained by them indicate a relatively low own price elasticity per SSB ( -0.85 for the entire sample and -1.03 in the group of the poorest), the authors estimated that with the introduction of approx. $30 \%$ of the tax, a significant effect on the reduction of SSB consumption will be expected to occur.

A slightly different line of research links the demand for sweetened drinks with the demand for unhealthy food. Thus, Colchero et al. (2015) conducted a study on Mexico based on the LA-AIDS model estimation results. They show that the demand for SSB is elastic (-1.16), and the cross-price elasticities show that an increase in SSB prices will result in increased interest in water and milk and a decrease in demand for unhealthy food (including snacks and candies).

Caro et al. (2017b), who used the QUAIDS model for the Chilean data, reached similar conclusions. Estimating the expected effects of changes in the consumption of junk food for three different scenarios of introducing the tax, they showed that the $18 \%$ tax will significantly affect the consumption of calories, and along with salty snacks $(-1.95)$, the demand for SSB will be of the greatest reduction $(-1.30)$.

Segovia et al. (2020), based on data from Ecuador, focused on examining the demand for non-alcoholic beverages divided into five groups: milk, water, sweetened drinks, juices, isotonic and energy drinks, and also coffee and tea. Their results show that SSBS are price elasticities $(-1.35$ for sweetened beverages and -1.11 for other SSBS like isotonic energy drinks), as well as a complementary relationship in the consumption of unhealthy beverages. The scenarios of introducing the tax ( $20 \%$ ad valorem or $18 \%$ by volume) considered by the au- 
thors indicate a significant (by 4540 and 3180, respectively) reduction in calories consumed.

For the data on recreation centres in Sheffield (UK), interesting results were obtained by Breeze et al. (2018). They showed that the effect of the change in SSB prices would be much greater (the price elasticity of demand was estimated at -3.753), if it is combined with a strong promotion of healthy eating (in the study, it was manifested, inter alia, through staff training, national and local advertising). A limitation of this study, however, is the fact that the data concern only a fraction of total purchases.

The effectiveness of the sugar tax is confirmed by the results obtained by Schmacker \& Smed (2020). Using the example of Denmark, where the fiscal strategy for soft drinks has changed in recent years, the authors showed that consumers responded in a similar way to both the growth and the abolition of the sugar tax (in both cases the elasticity was around -1.30).

Generally, the results obtained by the authors indicate that approx. 20\% of the tax may increase the price of sweetened beverages to such an extent that consumers limit their purchases. It turns out, however, that the introduction of the tax does not necessarily translate into the incidence of obesity and related diseases (Bes-Rastrollo et al., 2016; Cornelsen et al., 2019).

Among the reasons for this situation, the authors point to the fact that people most at risk of the consequences of a bad diet change their consumption habits rarely. The effectiveness of the pricing policy is also influenced by the level of tax transfer to retail prices (Cornelsen \& Smith, 2018) and the method of tax construction. Analysis Caro et al. (2017a) showed that taxes based on nutrients are more effective than taxing products.

\section{Methods}

\subsection{Dataset}

The source of information on the purchased quantities and household expenditure on the categories of goods specified in the survey are unpublished unit data from the Household Budget Survey carried out by the Central Statistical Office in 2018.

This research is carried out based on a representative sample of 36,166 households, which are described with a lot of additional information (e.g., size, place of residence, belonging to a selected socioeconomic group). The family selected for the study documents all its incomes and expenses for one month, and such conduct is a source of information on the income earned and expenses incurred on the categories of goods specified in the study.

An important element in the preparation of data for the study is putting nonalcoholic beverages into categories. In the case of data for Poland, the main limitation is the categorization used by the Central Statistical Office, which does not 
allow, for example, for the separation of dietary or energy drinks used in some studies (Dharmasena \& Capps, 2012; Jithitikulchai \& Andreyeva, 2018).

Due to the possible breach of the assumption of weak separability, the authors also decided not to include snacks and sweets in the model (Caro et al., 2017b; Colchero et al., 2015).

In the empirical study, it was decided to designate the following five product groups:

- milk (defined in the test with codes 011411 and 011412);

- mineral and spring water (identified by the code: 012211);

- juices (defined by codes: 012231, 012232);

- SSB (defined with the code: 012221);

- other beverages (i.e., coffee, tea, cocoa, and powdered chocolate identified with codes: 012111, 012121, and 012131).

\subsection{Unit price}

Because households report only the quantity and total expenditure per sub-category, a practical problem how to build a demand model is the need to determine the unit price that is valid for all surveyed households. The natural solution, where the unit price obtained by the ratio of expenditure on a given good to the quantity purchased, is criticized both for possible measurement errors and for quality effects (Attanasio et al., 2013, p. 140).

In the case of nonlinear demand models (e.g., QUAIDS), the approach proposed by Deaton (1988) cannot be applied. The solution may be to adjust prices for regression results in relation to specific demographic variables (Cox \& Wohlgenant, 1986), which, however, does not consider the postulate that prices should be constant within the local market (Majumder et al., 2012).

This article is based on Aepli (2014) work. In his approach, in order to determine the unit price, the following regression equation has been proposed:

$$
\nu_{i}-\left(\nu_{i}\right)_{\text {med }}=\alpha_{i} D_{l}+\gamma_{i} D_{m}+\delta_{i} x+\delta_{i} x^{2}+\sum_{j=1}^{m} b_{i} Z_{i j}+\varepsilon_{i j},
$$

where:

$\nu_{i}$ - the unit value paid by household for item $i$ in month $m$ lives in region $l$,

$D_{1}$ - dummie for region,

$D_{m}$ - dummie for month,

$x$ - income ( $x^{2}$ the square of income),

$Z_{i j}$ - household characteristics.

Then, using a robust $\mathrm{M}$-estimator, equation (1) was estimated, and the median of the unit price was determined for each item and in every subgroup of households.

$$
\left(p_{i}\right)_{\text {med }}=\left(\nu_{i}\right)_{\text {med }}+\left(\varepsilon_{i}\right)_{\text {med }},
$$


where:

$\left(\nu_{i}\right)_{\text {med }}$ - the median of the unit price paid by household for item $i$ in month $m$ lives in region $l$,

$\left(\varepsilon_{i}\right)_{\text {med }}$ - the median of residuals from (1) for households for item $i$ in month $m$ lives in region $l$.

\subsection{Model}

The study adopted the concept of multi-stage budgeting, which in particular means that the demand for non-alcoholic beverages is independent of the demand for other food products. This condition requires the assumption of weak separability in preferences (Deaton \& Muellbauer, 1980a) and means that in the first stage, the consumer allocates expenditures between general groups (incl. food). In the second stage, the consumer chooses between food sub-categories, and finally in the third stage, between non-alcoholic drinks, conditional on the total beverage expenditure.

Among the wide range of demand systems, that can explain consumer preferences in the third stage, the most popular in practical applications is the almost ideal demand system (AIDS) proposed by Deaton \& Muellbauer (1980b). A limitation in the application of the AIDS model is the fact that it assumes the linear form of Engel curves. Unfortunately, this assumption for many food products is usually rejected (Attanasio et al., 2013; Lakkakula et al., 2016).

The solution may be the use of the QUAIDS model (Banks et al., 1997), which allows for a quadratic dependence of budget shares on total income. Its construction is based on the indirect utility function $V(\mathbf{p}, I)$.

$$
\ln V(\mathbf{p}, I)=\left[\left[\frac{\ln I-\ln a(\mathbf{p})}{b(\mathbf{p})}\right]^{-1}+\lambda(\mathbf{p})\right]^{-1},
$$

where:

I- total income,

$a(\mathbf{p}), b(\mathbf{p})$ and $\lambda(\mathbf{p})$ - price indices given by formula (4)-(6):

$$
\begin{aligned}
& \ln a(\mathbf{p})=a_{0}+\sum_{i=1}^{n} \alpha_{i} \ln p_{i}+0.5 \sum_{i=1}^{n} \sum_{j=1}^{n} \gamma_{i j} \ln p_{i} \ln p_{j}, \\
& \ln b(\mathbf{p})=b_{0}+\sum_{i=1}^{n} \beta_{i} \ln p_{i}, \\
& \lambda(\mathbf{p})=\lambda_{0}+\sum_{i=1}^{n} \lambda_{i} \ln p_{i} .
\end{aligned}
$$

Applying Roy's identity for formulas (3)-(6) allows to obtain the QUAIDS model equations (Banks et al., 1997): 


$$
\left\{\begin{array}{c}
w_{1}=\alpha_{1}+\sum_{j=1}^{n} \gamma_{1 j} \ln p_{j}+\beta_{1} \ln \frac{I}{a(\mathbf{p})}+\frac{\lambda_{1}}{b(\mathbf{p})}\left[\ln \frac{I}{a(\mathbf{p})}\right]^{2} \\
w_{2}=\alpha_{2}+\sum_{j=1}^{n} \gamma_{2 j} \ln p_{j}+\beta_{2} \ln \frac{I}{a(\mathbf{p})}+\frac{\lambda_{2}}{b(\mathbf{p})}\left[\ln \frac{I}{a(\mathbf{p})}\right]^{2} \\
K \\
w_{n}=\alpha_{n}+\sum_{j=1}^{n} \gamma_{n j} \ln p_{j}+\beta_{n} \ln \frac{I}{a(\mathbf{p})}+\frac{\lambda_{n}}{b(\mathbf{p})}\left[\ln \frac{I}{a(\mathbf{p})}\right]^{2}
\end{array}\right.
$$

where:

$w_{i}$ - the budget shares,

$p_{i}$ - the unit prices of individual goods,

$I$ - the household income,

$n-$ the number of considered goods.

The advantage of the demand systems is the possibility of introducing into the model conditions that ensure the fulfilment of the assumptions of the theory of consumer choice. In the case of the QUAIDS model, these requirements are imposed by linear constraints on the model parameters. Assuming the conditions of additivity, zero-degree homogeneity with respect to prices, and symmetry of substitution effects, we obtain the following set of restrictions

$$
\sum_{i=1}^{n} \alpha_{i}=1, \sum_{i=1}^{n} \beta_{i}=0, \sum_{i=1}^{n} \gamma_{i j}=0, \sum_{i=1}^{n} \lambda_{i}=0 \text { and } \gamma_{i j}=\gamma_{j i} \text {. }
$$

\subsection{Demographics variables in QUAIDS model}

Using cross-sectional data indicates that the diversity of households is not only related to the expenditure and prices. The variability relates to age, sex or the number and age of children, but also for other demographic variables (e.g., place of residence, education, or profession). Deaton \& Muellbauer (1980a) noted that, fully satisfactory models of the behaviour of households need to consider the characteristics of households.

There are two main ways to introduce these variables into the demand model: the "scaling approach" (Ray, 1983) and the "translating approach" (Pollak \& Wales, 1981). The work uses an translating approach in which household heterogeneity enters the demand system through $\alpha$ coefficients, which are modelled as linear combinations of a set of demographic variables.

\subsection{Price and income elasticities of demand in QUAIDS}

One of the main goals of estimating demand models is the fact that its parameters allow for the obtaining income elasticities $\left(\eta_{i}\right)$ and uncompensated $\left(\varepsilon_{i j}\right)$ price 
elasticities of demand (Lecocq \& Robin, 2015). The corresponding formulas are obtained from:

$$
\begin{aligned}
& \eta_{i}=1+\frac{\mu_{i}}{w_{i}}, \\
& \varepsilon_{i j}=\frac{\mu_{i j}}{w_{i}}-\delta_{i j},
\end{aligned}
$$

where $\delta_{i j}$ is the Kronecker delta, and $\mu_{i}$ and $\mu_{i j}$ are obtained by differentiation the model equations with respect to the logarithm of the total income $(I)$ or price $\left(p_{j}\right)$ :

$$
\begin{aligned}
& \mu_{i}=\frac{\partial w_{i}}{\partial I}=\beta_{i}+\frac{2 \lambda_{i}}{b(\mathbf{p})} \ln \left(\frac{I}{b(\mathbf{p})}\right), \\
& \mu_{i j}=\frac{\partial w_{i}}{\partial \ln p_{j}}=\gamma_{i j}-\mu_{i}\left(\alpha_{i}+\sum_{j=1}^{n} \gamma_{i j} \ln p_{j}\right)-\frac{\beta_{i} \lambda_{i}}{b(\mathbf{p})}\left[\ln \left(\frac{I}{a(\mathbf{p})}\right)\right]^{2} .
\end{aligned}
$$

\section{Results}

The first stage of the empirical study was the preparation of data for analysis. After extracting the purchased quantities and determining the total expenses for individual categories of nonalcohol beverages, it was decided to remove $1 \%$ of extreme cases in a sense of total expenditure.

In the next step, the unit price was carried out. Based on Aepli (2014), the following demographic variables were adopted in equation (1): socio-economic group, education of the head of the family and family size. Due to some limitations in the CSO data, the combination of the voivodship and the size of the place of residence was assumed as region $l$.

Table 1 shows the descriptive statistics for shares, prices, and consumption quantity of non-alcoholic beverages. As can be seen, expenses for sweetened drinks represent about $22 \%$ of the total budget on non-alcoholic drinks, and by volume constitute for over 10 litres per month.

Next, economics restrictions were imposed on the parameters of the model given by system of equations (6). Also, according to the Pollak \& Wales (1981) technique, a demographic variable (family size) was introduced to the model. The results were obtained using the ILLS estimator and the algorithm proposed by Lecocq \& Robin (2015).

Parameters obtained during the estimation (Table 2) show the dependence of budget shares on the square of total expenditure (all apart from the milk equation are nonzero at a significance level of 0.01). Moreover, parameters of the demographic variable - outside the equation for juices - imposed into the model are significant at 0.01 level. It means that the estimation of QUAIDS with a demographic variable is correct. 
Uncompensated own-price elasticities (Table 3) indicate a more than proportional impact of price changes on consumption in three categories: water, juices, and sweetened beverages. Moreover, for the group of other drinks (i.e., coffee, tea, cocoa), the change is nearly proportional. In the case of SSB, the estimated own price elasticity means that with a 25 percent increase in the price (current estimates on the Polish market), the demand for them will decrease by approximately 33 percent.

The introduction of the sugar tax also may have a positive impact on the structure of consumption of non-alcoholic beverages. Obtained cross-elasticities of demand indicate complementary relations between SSB and water (0.373) and between SSB and juices (0.408). By releasing high-quality juices from the tax, the government seems to have created an opportunity to replace unhealthy drinks with either mineral water or juices.

The demand elasticity estimates presented in Table 4 show that in Poland all types of non-alcoholic beverages are normal goods (i.e., income elasticity is greater than zero) and indicate an approximately proportional impact of income changes on consumption. The highest estimate was given to SSB (1.279) and juices (1.117), which means that as income increases, consumers will be more interested in consuming these categories of beverages.

\section{Discussion}

Based on the results of the QUAIDS estimation model, estimates of the price and income elasticities of demand for five subgroups of beverages (milk, water, juice, SSB, and others) were obtained. It turned out that the demand for SSB in Poland is price elastic (-1.318). It was further concluded that the increase in SSB prices would have a significant impact on the structure of nonalcoholic drink consumption, which would also lead to an increase in demand for water and juices.

According to our knowledge, this is the first publication in which the model of demand for soft drinks in Poland has been estimated. This means that the results can only be compared with foreign studies. The own-price elasticities derived for SSB appears to be like those obtained by other authors, i.e., Schmacker \& Smed (2020) results for Denmark (-1.30), Segovia et al. (2020), results for Ecuador (-1.35), and Guerrero-López et al. (2017) for Chile (-1.37).

Cross-price demand elasticities show that water and juice are complementary goods for the SSB. While the results obtained in this paper generally support other studies (Colchero et al., 2015; Dharmasena \& Capps, 2012), for juices in the literature there is no consistent evidence. Many studies (Escobar et al., 2013) generally do not support the resulting substitution relationship between SSB and milk.

Of course, the real consumer response does not depend solely on the relative price movements of soft drinks. Despite the first information from the Polish market, it is not yet clear to what extent the tax will be passed on to detail prices. 
Numerous foreign studies (Breeze et al., 2018) show a significant relationship between the introduced taxes and the campaign promoting a healthy lifestyle. And although, because of objective reasons, it is currently not possible to promote physical activity (coronavirus epidemy), the lack of large, nationwide programs to encourage diet change should be noted with some concern.

\section{Conclusion}

The main purpose of the study was to answer the question of how Polish consumers will react to price changes caused by the introduction of the sugar tax. The research tool used in the study was the estimation of the QUAIDS model using data from the household budget survey conducted by the Central Statistical Office in 2018 and the interpretation of the obtained price and income estimates of demand elasticity.

The results indicate that consumer reactions depend on the category of non-alcoholic beverages considered, and it was concluded that the introduction of the sugar tax should effectively limit the consumption of SSBS due to their flexible demand behaviour. It has been estimated that in response to the $25 \%$ increase in the price of sweetened beverages, the demand will be reduced by approx. 33\%. Additionally, the analysis of the cross-price elasticity shows possible directions of changes in the consumption habits. It seems that the increase in SSB prices will affect the increased demand for water $(0.373)$ and juices (0.408). In this context, it seems reasonable that the legislators made the imposition of a tax on juices dependent on their quality.

The obtained results are subject to some limitations. First, the data set used to estimate the model shows only home consumption, and the subcategories adopted by the Central Statistical Office make it impossible to distinguish more precisely sweetened drinks (e.g., into carbonated drinks, energy drinks, diet drinks). This means that it is not possible to check the substitution relationships between the different types of SSB, and the impact of the individual tax components (e.g., additional charges for the presence of active substances) cannot be accurately determined. The access to scanner data seems to be the solution to this problem, see Dharmasena \& Capps (2012).

The paper assumes that consumption behaviour is similar for all age and income groups. An interesting supplement to the research would be the analysis of consumer behaviour, e.g., categorized into income groups (Paraje, 2016) and age groups (Briggs et al., 2013).

The model was estimated based on the assumption of weak separability of preferences. Thus, it was assumed that there is no relationship between the consumption of non-alcoholic beverages and the purchase of other food, e.g., junk food. The results so far (Caro et al., 2017b; Colchero et al., 2015) do not conclude whether this assumption is met.

Due to the lack of up-to-date data, it was impossible to compare how the obtained estimates coincided with the actual changes in the consumption of indi- 
vidual categories of non-alcoholic beverages after the introduction of the sugar tax in Poland.

The limitations described above can be the starting point for extending the results obtained in the study. It seems that the analysis of the demand for sweetened beverages in various income and age groups, as well as the use of data from other sources (i.e., scanner data) to study the demand dependencies between different types of soft drinks, may be particularly interesting.

\section{References}

Aepli, M. (2014). Consumer demand for alcoholic beverages in Switzerland: a two-stage quadratic almost ideal demand system for low, moderate, and heavy drinking households. Agricultural and Food Economics, 2(1), 1-27. https://doi.org/10.1186/s40100-014-0015-0.

Attanasio, O., Di Maro, V., Lechene, V., \& Phillips, D. (2013). Welfare consequences of food price increases: evidence from rural Mexico. Journal of Development Economics, 104, 136-151. https://doi.org/10.1016/j. jdeveco.2013.03.009.

Banks, J., Blundell, R., \& Lewbel, A. (1997). Quadratic Engel curves and consumer demand. Review of Economics and Statistics, 79(4), 527-539. https:// doi.org/10.1162/003465397557015.

Barrientos-Gutierrez, T., Zepeda-Tello, R., Rodrigues, E.R., Colchero-Aragones, A., Rojas-Martínez, R., Lazcano-Ponce, E., Mauricio Hernández-Ávila, M., \& Meza, R. (2017). Expected population weight and diabetes impact of the 1-peso-per-litre tax on sugar-sweetened beverages in Mexico. Plos One, 12(5), e0176336. https://doi.org/10.1371/journal.pone.0176336.

Bernardi, N., Sevestre, P., Tépaut, M. \& Vigneron, A. (2016) The impact of a 'soda tax' on prices: evidence from French micro data. Applied Economics, 48(41), 3976-3994. https://doi.org/10.1080/00036846.2016.115094 6.

Bes-Rastrollo, M., Sayon-Orea, C., Ruiz-Canela, M., \& Martinez-Gonzalez, M.A. (2016), Impact of sugars and sugar taxation on body weight control: a comprehensive literature review. Obesity, 24(7), 1410-1426. https://doi. org/10.1002/oby.21535.

Bíró, A. (2015). Did the junk food tax make the Hungarians eat healthier. Food Policy, 54, 107-115. https://doi.org/10.1016/j.foodpol.2015.05.003.

Blake, M.R., Lancsar, E., Peeters, A., \& Backholer, K. (2019). Sugar-sweetened beverage price elasticity in a hypothetical convenience store. Social Science e Medicine, 225, 98-107. https://doi.org/10.1016/j.socscimed.2019.02.021.

Bødker, M., Pisinger, C., Toft, U., \& Jørgensen, T. (2015). The Danish fat tax: effects on consumption patterns and risk of ischaemic heart disease. Preventive Medicine, 77, 200-203. https://doi.org/10.1016/j.ypmed.2015.03.031. 
Breeze, P., Womack, R., Pryce, R., Brennan, A., \& Goyder, E. (2018). The impact of a local sugar sweetened beverage health promotion and price increase on sales in public leisure centre facilities. Plos One, 13(5), e0194637. https:// doi.org/10.1371/journal.pone.0194637.

Briggs, A.D., Mytton, O.T., Kehlbacher, A., Tiffin, R., Rayner, M., \& Scarborough, P. (2013). Overall and income specific effects on the prevalence of overweight and obesity of $20 \%$ sugar sweetened drink tax in UK: econometric and comparative risk assessment modelling study. BMJ, 347, f6189. https://doi.org/10.1136/bmj.f6189.

Caro, J.C., Ng, S.W., Bonilla, R., Tovar, J., \& Popkin, B.M. (2017a). Sugary drink taxation, projected consumption and fiscal revenues in Colombia: evidence from a QUAIDS model. Plos One, 12(12), e0189026. https://doi. org/10.1371/journal.pone.0189026.

Caro, J.C., Ng, S.W., Taillie L.S., \& Popkin, B.M. (2017b). Designing a tax to discourage unhealthy food and beverage purchases: the case of Chile. Food Policy, 71, 86-100. https://doi.org/10.1016/j.foodpol.2017.08.001.

Cawley, J., Frisvold, D., Hill, A., \& Jones, D. (2019). The impact of the Philadelphia beverage tax on purchases and consumption by adults and children. Journal of Health Economics, 67, 102225. https://doi.org/10.1016/j. jhealeco.2019.102225.

Claro, R.M., Levy, R.B., Popkin, B.M., \& Monteiro, C.A. (2012). Sugar-sweetened beverage taxes in Brazil. American Journal of Public Health, 102(1), 178183. https://doi.org/10.2105/ajph.2011.300313.

Colchero, M.A., Salgado J.C., Unar-Munguía, M., Hernández-Ávila, M., \& Rivera-Dommarco, J.A. (2015). Price elasticity of the demand for sugar-sweetened beverages and soft drinks in Mexico. Economics \& Human Biology, 19, 129-137. https://doi.org/10.1016/j.ehb.2015.08.007.

Cornelsen, L., \& Smith, R.D. (2018). Viewpoint: Soda taxes: for questions economists need to address. Food Policy, 74, 138-142. https://doi.org/10.1016/j. foodpol.2017.12.003.

Cornelsen, L., Mazzocchi, M., \& Smith, R.D. (2019), Fat tax or thin subsidy: how price increases and decreases affect the energy and nutrient content of food and beverage purchases in Great Britain. Social Science \& Medicine, 230, 318-327. https://doi.org/10.1016/j.socscimed.2019.04.003.

Cox, T.L., \& Wohlgenant, M.K. (1986). Prices and quality effects in cross-sectional demand analysis. American Journal of Agricultural Economics, 68(4), 908-919. https://doi.org/10.2307/1242137.

Deaton, A. (1988). Quality, quantity, and spatial variation of price. The American Economic Review, 78(3), 418-430.

Deaton, A., \& Muellbauer, J. (1980a). An almost ideal demand system. The American Economic Review, 70(3), 312-326.

Deaton, A., \& Muellbauer, J. (1980b). Economics and Consumer Behavior. Cambridge University Press. 
Dharmasena, S., \& Capps, O. (2012). Intended and unintended consequences of the proposed national tax on sugar-sweetened beverages to combat the U.S. obesity problem. Health Economics, 21(6), 669-694. https://doi. org/10.1002/hec.1738.

Escobar, M.A.C., Veerman, J.L., Tollman, S.M., Bertram, M.Y., \& Hofman, K.J. (2013). Evidence that a tax on sugar-sweetened beverages reduces the obesity rate: a meta-analysis. BMC Public Health, 13(1), 1-10. https:// doi.org/10.1186/1471-2458-13-1072.

Finkelstein, E.A., Zhen, C., Nonnemaker, J., \& Todd, J.E. (2010). Impact of targeted beverage taxes on higher- and lower-income households. Archives of Internal Medicine, 170(22), 2028-2034. https://doi.org/10.1001/ archinternmed.2010.449.

Guerrero-López, C.M., Unar-Munguía, M., \& Colchero, M.A. (2017). Price elasticity of the demand for soft drinks, other sugar-sweetened beverages, and energy dense food in Chile. BMC Public Health, 17(1), 1-8. https://doi. org/10.1186/s12889-017-4098-x.

Harding, M., \& Lovenheim, M. (2017). The effect of prices on nutrition: comparing the impact of product- and nutrient-specific taxes. Journal of Health Economics, 53, 53-71. https://doi.org/10.1016/j.jhealeco.2017.02.003.

Härkänen, T., Kotakorpi, K., Pietinen, P., Pirttilä, J., Reinivuo, H., \& Suoniemi, I. (2014). The welfare effects of health-based food tax policy. Food Policy, 49(1), 196-206. https://doi.org/10.1016/j.foodpol.2014.07.001.

Jithitikulchai, T., \& Andreyeva, T. (2018). Sugar-sweetened beverage demand and tax simulation for federal food assistance participants: a case of two new England states. Applied Health Economics and Health Policy, 16(4), 549-558. https://doi.org/10.1007/s40258-018-0399-1.

Lakkakula, P., Schmitz, A., \& Ripplinger, D. (2016). U.S. sweetener demand analysis: a QUAIDS model application. Journal of Agricultural and Resource Economics, 41(3), 533-548.

Lecocq, S., \& Robin, J.-M. (2015). Estimating almost-ideal demand systems with endogenous regressors. The Stata Journal, 15(2), 554-573. https://doi. org/10.1177/1536867x1501500214.

Lin, B.H., Smith, T.A., \& Lee, Y.J. (2011). Measuring weight outcomes for obesity intervention strategies: the case of a sugar-sweetened beverage tax. Economics \& Human Biology, 9(4), 329-341. https://doi.org/10.1016/j. ehb.2011.08.007.

Majumder, A., Ray, R., \& Sinha, K. (2012). Calculating rural-urban food price differentials from unit values in household expenditure surveys: a comparison with existing methods and a new procedure. American Journal of Agricultural Economics, 94(5), 1218-1235. https://doi.org/10.1093/ajae/aas064.

Malik, V.S., Popkin, B.M., Bray, G.A., Després, J.P., \& Hu, F.B. (2010). Sugar-sweetened beverages, obesity, type 2 diabetes mellitus, and cardiovascular disease risk. Circulation, 121(11), 1356-1364. https://doi.org/10.1161/ circulationaha.109.876185. 
Malik, V.S., Schulze, M.B., \& Hu, F.B. (2006). Intake of sugar-sweetened beverages and weight gain: a systematic review. The American Journal Of Clinical Nutrition, 84(2), 274-288. https://doi.org/10.1093/ajcn/84.1.274.

Manyema, M., Veerman, L.J., Chola, L., Tugendhaft, A., Sartorius, B., Labadarios, D., \& Hofman, K.J. (2014). The potential impact of a 20\% tax on sugar-sweetened beverages on obesity in South African adults: a mathematical model. Plos One, 9(8), el05287. https://doi.org/10.1371/journal. pone.0105287.

Miller, C., Wakefield, M., Braunack-Mayer, A., Roder, D., O’Dea, K., Ettridge, K., \& Dono, J. (2019). Who drinks sugar, sweetened beverages, and juice: an Australian population study of behaviour, awareness and attitudes. BMC Obesity, 6(1), 1-12. https://doi.org/10.1186/s40608-018-0224-2.

Paraje, G. (2016). The effect of price and socio-economic level on the consumption of sugar-sweetened beverages (SSB): the case of Ecuador. Plos One, 11(3), e0152260. https://doi.org/10.1371/journal.pone.0152260.

Pollak, R.A., \& Wales, T.J. (1981) Demographic variables in demand analysis. Econometrica, 49(6), 1533-1551. https://doi.org/10.2307/1911416.

Ray, R. (1983). Measuring the cost of children: an alternative approach. Journal of Public Economics, 22(1), 89-102. https://doi. org/10.1016/0047-2727(83)90058-0.

Schmacker, R., \& Smed, S. (2020). Do prices and purchases respond similarly to soft drink tax increases and cuts. Economics \& Human Biology, 37, 100864. https://doi.org/10.1016/j.ehb.2020.100864.

Segovia, J., Orellana, M., Sarmiento, J.P., \& Carchi, D. (2020). The effects of taxing sugar-sweetened beverages in Ecuador: an analysis across different income and consumption groups. Plos One, 15(10), e0240546. https://doi. org/10.1371/journal.pone.0240546.

Smed, S., Scarborough, P., Rayner, M., \& Jensen, J.D. (2016). The effects of the Danish saturated fat tax on food and nutrient intake and modelled health outcomes: econometric and comparative risk assessment evaluation. European Journal of Clinical Nutrition, 70(6), 681-686. https://doi. org/10.1038/ejcn.2016.6.

Vecino-Ortiz, A.I., \& Arroyo-Ariza, D. (2018). A tax on sugar sweetened beverages in Colombia: estimating the impact on overweight and obesity prevalence across socio-economic levels. Social Science \& Medicine, 209, 111-116. https://doi.org/10.1016/j.socscimed.2018.05.043.

\section{Acknowledgements}

Author contributions: author has given an approval to the final version of the article.

Funding: this research was fully funded by the AGH University of Science and Technology in Kraków (institutional subsidy for maintaining Research Capacity Grant 11|11.200.325).

Note: the results of this study were presented at 11th International Conference on Applied Economics Contemporary Issues in Economy (June 17-18, 2021, online, Poland). 


\section{Appendix}

Table 1.

Expenditure, price, and consumption descriptive statistics

\begin{tabular}{|c|c|c|c|}
\hline Category & Mean & Standard deviation & Median \\
\hline \multicolumn{4}{|c|}{ Expenditure shares } \\
\hline milk & 0.15 & 0.18 & 0.10 \\
\hline water & 0.19 & 0.19 & 0.15 \\
\hline juice & 0.10 & 0.14 & 0.05 \\
\hline ssb & 0.22 & 0.21 & 0.18 \\
\hline other & 0.34 & 0.24 & 0.31 \\
\hline \multicolumn{4}{|c|}{ Unit values — quality adjusted (PLN/liter) } \\
\hline milk & 2.22 & 0.15 & 2.20 \\
\hline water & 1.01 & 0.10 & 1.01 \\
\hline juice & 3.11 & 0.45 & 3.04 \\
\hline ssb & 1.87 & 0.41 & 1.78 \\
\hline other & 35.52 & 6.85 & 34.06 \\
\hline \multicolumn{4}{|c|}{ Per capita quantity (liter/month) } \\
\hline milk & 5.34 & 7.51 & 3.00 \\
\hline water & 15.32 & 18.68 & 9.00 \\
\hline juice & 2.56 & 4.37 & 1.00 \\
\hline $\mathrm{ssb}$ & 10.25 & 14.44 & 5.00 \\
\hline other & 0.67 & 0.65 & 0.50 \\
\hline
\end{tabular}

Source: Own calculation based on unit data from Household Budget Survey in 2018.

Table 2.

Results of QUAIDS demand system (7)-(8) estimation

\begin{tabular}{lccccc}
\hline Category & $w_{1}$ & $w_{2}$ & $w_{3}$ & $w_{4}$ & $w_{5}$ \\
\hline milk price $\left(\gamma_{i 1}\right)$ & $0.13^{* *}$ & 0.015 & $-0.050^{* *}$ & $-0.072^{* *}$ & $-0.024^{* *}$ \\
& $(0.011)$ & $(0.011)$ & $(0.008)$ & $(0.008)$ & $(0.008)$ \\
water price $\left(\gamma_{i 2}\right)$ & 0.015 & $-0.111^{* *}$ & -0.010 & $0.053^{* *}$ & $-0.047^{* *}$ \\
& $(0.011)$ & $(0.012)$ & $(0.008)$ & $(0.009)$ & $(0.013)$ \\
juice price $\left(\gamma_{i 3}\right)$ & $-0.050^{* *}$ & -0.010 & -0.002 & $0.055^{* *}$ & 0.008 \\
& $(0.008)$ & $(0.008)$ & $(0.006)$ & $(0.006)$ & $(0.007)$ \\
ssb price $\left(\gamma_{i 4}\right)$ & $-0.072^{* *}$ & $0.053^{* *}$ & $0.055^{* *}$ & $0.054^{* *}$ & $-0.009^{* *}$ \\
& $(0.008)$ & $(0.009)$ & $(0.006)$ & $(0.013)$ & $(0.012)$ \\
other price $\left(\gamma_{i 5}\right)$ & $-0.024^{* *}$ & $0.053^{* *}$ & 0.008 & $-0.009^{* *}$ & $0.053^{* *}$ \\
& $(0.008)$ & $(0.009)$ & $(0.007)$ & $(0.012)$ & $(0.014)$ \\
income $\left(\beta_{i}\right)$ & $-0.028^{* *}$ & $-0.047^{* *}$ & $0.039^{* *}$ & $0.167^{* *}$ & $-0.131^{* *}$ \\
income^2$\left(\lambda_{i}\right)$ & $(0.012)$ & $(0.013)$ & $(0.009)$ & $(0.013)$ & $(0.013)$ \\
& 0.000 & $-0.002^{* *}$ & $0.002^{* *}$ & $0.007^{* *}$ & $-0.007^{* *}$ \\
constant $($ person $)\left(\alpha_{i p}\right)$ & $(0.001)$ & $(0.001)$ & $(0.000)$ & $(0.001)$ & $(0.001)$ \\
constant $(\alpha)$ & $0.009^{* *}$ & 0.000 & $0.003^{* *}$ & $0.017^{* *}$ & $-0.028^{* *}$ \\
& $(0.000)$ & $(0.001)$ & $(0.001)$ & $(0.001)$ & $(0.001)$ \\
& 0.064 & $-0.178^{* *}$ & $0.203^{* *}$ & $1.015^{* *}$ & -0.102
\end{tabular}

Notes:

Standard error in parentheses. ${ }^{*} \mathrm{p}<0.05 ;{ }^{* *} \mathrm{p}<0.01$.

Source: Own calculation based on unit data from Household Budget Survey in 2018. 
Table 3.

Uncompensated (Marshallian) price elasticities

\begin{tabular}{lccccc}
\hline \multicolumn{1}{c}{ Category } & Milk price & Water price & Juice price & SSB price & Other price \\
\hline milk share & $-0.217^{*}$ & 0.091 & $-0.265^{* *}$ & $-0.237^{* *}$ & $-0.162^{* *}$ \\
& $(0.074)$ & $(0.066)$ & $(0.047)$ & $(0.044)$ & $(0.040)$ \\
water share & 0.053 & $-1.540^{* *}$ & -0.017 & $0.373^{* *}$ & $0.171^{* *}$ \\
& $(0.053)$ & $(0.054)$ & $(0.038)$ & $(0.030)$ & $(0.030)$ \\
juice share & $-0.604^{* *}$ & -0.081 & $-1.099^{* *}$ & $0.408^{* *}$ & $0.260^{* *}$ \\
& $(0.106)$ & $(0.106)$ & $(0.074)$ & $(0.058)$ & $(0.007)$ \\
ssb share & $-0.446^{* *}$ & $0.522^{* *}$ & $0.223^{* *}$ & $-1.318^{* *}$ & $-0.261^{* *}$ \\
& $(0.091)$ & $(0.099)$ & $(0.065)$ & $(0.060)$ & $(0.060)$ \\
other share & $-0.084^{*}$ & $0.091^{*}$ & $0.063^{*}$ & $-0.045^{*}$ & $-0.987^{* *}$ \\
& $(0.036)$ & $(0.037)$ & $(0.025)$ & $(0.022)$ & $(0.022)$ \\
\hline
\end{tabular}

Notes:

Standard error in parentheses. ${ }^{*} \mathrm{p}<0.05 ;{ }^{* *} \mathrm{p}<0.01$.

Source: Own calculation based on unit data from Household Budget Survey in 2018.

Table 4.

Income price elasticities

\begin{tabular}{|c|c|c|c|c|c|}
\hline Category & Milk price & Water price & Juice price & SSB price & Other price \\
\hline \multirow{2}{*}{ income elasticity } & $0.860^{* *}$ & $0.960^{* *}$ & $1.117^{* *}$ & $1.279^{* *}$ & $0.963^{* *}$ \\
\hline & $(0.006)$ & $(0.009)$ & $(0.025)$ & $(0.029)$ & $(0.006)$ \\
\hline
\end{tabular}

Notes:

Standard error in parentheses. ${ }^{*} \mathrm{p}<0.05 ;{ }^{* *} \mathrm{p}<0.01$.

Source: Own calculation based on unit data from Household Budget Survey in 2018. 
